\title{
Taurine and Osmoregulation. III. Taurine Deficiency Protects against Cerebral Edema during Acute Hyponatremia ${ }^{1}$
}

\author{
HOWARD TRACHTMAN, RICHARD DEL PIZZO, AND JOHN A. STURMAN \\ Department of Pediatrics, Division of Nephrology, Schneider Children's Hospital of Long Island Jewish Medical \\ Center, New Hyde Park, New York 11042; State University of New York at Stony Brook; Department of \\ Developmental Biochemistry, Institute for Basic Research in Developmental Disabilities,
} Staten Island, New York 10314

\begin{abstract}
Taurine is a cerebral osmoprotective molecule during chronic hypernatremic dehydration. In these experiments, we investigated the role of taurine in osmoregulation during acute hyponatremia. Taurine deficiency was induced in experimental cats $(n=6)$ by feeding a taurine-free diet for 8-10 wk, whereas control counterparts $(n=6)$ consumed a regular diet. Hyponatremia was provoked in all cats over $54 \mathrm{~h}$ by daily injections of $5 \%$ dextrose in water $(7.5 \%$ body wt) and vasopressin $(20 \mathrm{U} /$ d). The serum $\mathrm{Na}^{+}$concentration was abruptly lowered to $110 \pm 3$ and $117 \pm 2 \mathrm{mmol} / \mathrm{L}$, in experimental and control animals, respectively. The cerebral total and intracellular water compartment sizes were reduced from $486 \pm 11$ to $441 \pm 11 \mathrm{ml} / 100 \mathrm{~g}$ dry wt and from $357 \pm 7$ to $309 \pm 12$ $\mathrm{mL} / 100 \mathrm{~g}$ dry wt, respectively, in control versus experimental cats, $p<0.05$. There was a significant linear relationship between cerebral taurine content and the intracellular water compartment size in all animals, $p<0.02$. Taurine displayed a similar osmoprotective capacity in muscle tissue in these studies. We conclude that taurine is an osmoregulatory molecule in cerebral and extracerebral tissues during severe hyponatremia. Reductions in tissue taurine content may complement decreases in cytosolic electrolyte levels during adaptation to more prolonged hyponatremia. (Pediatr Res 27: 85-88, 1990)
\end{abstract}

Abbreviations

ECW, extracellular water

ICW, intracellular water

TTW, total tissue water

Taurine is a sulfur amino acid found in all organs. It is frequently the most abundant free amino acid in the cell (1). Work by Thurston et al. (2) suggested that one of taurine's important functions is to serve as a brain osmolyte during sustained hypernatremia. Recently, we directly demonstrated that taurine is a cerebral osmoregulatory molecule that limits brain cell shrinkage during chronic hypernatremic dehydration (3). Indirect evidence suggests that taurine may also be involved in osmoregulation in hypoosmolal states. For example, in mice

Received April 6, 1989; accepted August 17, 1989

Correspondence Dr. Howard Trachtman, Division of Nephrology, Schneider Children's Hospital, 271-16 76th Ave., New Hyde Park, NY 11042.

Portions of this work were presented at the First Annual Meeting of the Eastern Society of Pediatric Research held in New York, October 1988. with chronic hyponatremic and a mean serum $\mathrm{Na}^{+}$concentration of $104 \mathrm{mmol} / \mathrm{L}$, the cerebral taurine concentration declined by $70 \%$ and accounted for most of the fall in brain cytosolic free amino acid content (4). Therefore, we conducted the following experiments to directly determine whether taurine serves as a cerebral osmoprotective molecule in acute hyponatremia. We predicted that cerebral taurine depletion would diminish brain swelling during the sudden osmolal disturbance.

Cats were used in the studies because their brain taurine content can be readily manipulated by eliminating the amino acid from the diet (5). This is a consequence of limited cerebral taurine biosynthetic capacity in cats due to low activity of the enzyme cysteine sulfinic acid decarboxylase. In addition, in feline species, there is obligatory use of taurine as a bile acid conjugate (6). These unique features of the cat's nutritional capabilities make it an ideal species for studying the osmoregulatory functions of taurine.

\section{MATERIALS AND METHODS}

Animals. Cats weighing 1-3 kg were obtained from a breeding colony at the State University of New York, Health Sciences Center at Brooklyn. The animals were conditioned and vaccinated against routine viral pathogens and weaned at 8-10 wk of age. When the cats reached 4 mo of age, they were randomized to one of two study groups, either a control group $(n=6)$ or a taurine-free diet group $(n=6)$. The control taurine replete containing $0.05 \%$ taurine by weight and taurine-free diets were prepared in color-coded pelleted form (Bio-Serv, Inc., Frenchtown, $\mathrm{NJ}$ ). The animals were given tap water to drink ad libitum. The dietary preconditioning phase was maintained for $12 \mathrm{wk}$ before commencing the acute studies.

Procedures. Hyponatremia was induced over $54 \mathrm{~h}$ by the daily intramuscular injection of vasopressin tannate in oil $10 \mathrm{U} /$ day and aqueous vasopressin $10 \mathrm{U} /$ day (Parke-Davis, Morris Plains, $\mathrm{NJ})$. In addition, cats were given $5 \%$ dextrose in water, in an amount equal to $7.5 \%$ of body wt per day in two intraperitoneal injections. After obtaining blood by cardiac puncture, animals were killed at $54 \mathrm{~h}$ by injecting a euthanasia solution. Portions of the vastus medialis muscle and the entire brain were rapidly removed. A segment of excised tissues was dried to constant weight at $75^{\circ} \mathrm{C}$ for $72 \mathrm{~h}$ to calculate the TTW, i.e. wet wt - dry wt. A second portion was weighed and dissolved in $5 \mathrm{~N} \mathrm{HNO}_{3}$ for $7 \mathrm{~d}$ for electrolyte analysis $(2,3)$. A third portion was tared and homogenized in $10 \%$ trichloroacetic acid (9:1, vol:wt) for measurement of tissue taurine content.

Chemical analysis. Serum and tissue electrolyte measurements, before and at completion of the study, were performed using an automated analyzer (Beckman Instruments Inc., Fuller- 
ton, CA). Plasma and tissue taurine levels were determined using reverse-phase HPLC with precolumn derivatization with phenylisothiocyanate and quantified using Nelson Analytical 2600 chromatography software with an IBM PC-AT (IBM Instruments, Inc., Danbury, CT).

Calculations. The ECW space was calculated as the chloride space (7). The ICW compartment size was derived by the formula, ICW $=$ TTW - ECW. All tissue ${ }^{r}$, ater compartment sizes are expressed as $\mathrm{mL} / 100 \mathrm{~g}$ dry wt. The plasma and tissue taurine levels are expressed as $\mu \mathrm{mol} / 100 \mathrm{~m}^{\mathrm{I}}$. and $\mu \mathrm{mol} / \mathrm{g}$ wet tissue wt, respectively.

Statistical analysis. Differences in mean values of the control and experimental groups were compared using a paired $t$ tests and were considered statistically significant if the $p$ value was less than 0.05 . Relationships between variables were assessed using linear regression analysis.

\section{RESULTS}

The cats adapted well to both pelleted diets; all animals thrived with normal weight gain patterns during the 12-wk pretreatment period before induction of acute hyponatremia.

The acute hyponatremia regimen was successful in achieving its goal (Table 1). None of the cats died prematurely; furthermore, whereas they exhibited a lethargic appearance with disheveled fur, no overt neurologic dysfunction was observed in any animal. The percentage weight gain was similar in both groups. In addition, whereas the final serum $\mathrm{Na}^{+}$concentration and calculated osmolality were lower in the taurine-deficient cats, the differences between groups were not statistically significant. It should be noted that the lower final serum $\mathrm{Na}^{+}$concen-

Table 1. General animal data (mean \pm SEM)

\begin{tabular}{lcc}
\hline & $\begin{array}{c}\text { Hyponatremic } \\
\text { taurine replete } \\
(n=6)\end{array}$ & $\begin{array}{c}\text { Hyponatremic } \\
\text { taurine deficient } \\
(n=6)\end{array}$ \\
\hline Wt $(\mathrm{g})$ & $4471 \pm 361$ & $5080 \pm 1074$ \\
Pre & $4804 \pm 463$ & $5535 \pm 1298$ \\
Final & $6.5 \pm 2.1$ & $6.7 \pm 3.3$ \\
\% Increase & & \\
Serum Na+* $(\mathrm{mmol} / \mathrm{L})$ & $153 \pm 1$ & $153 \pm 1$ \\
Pre & $117 \pm 2 \dagger$ & $110 \pm 3 \dagger$ \\
Final &
\end{tabular}

* Normal range: $145-155 \mathrm{mmol} / \mathrm{L}$ (Am. Assoc. Lab. Animals) Science 1988 (publication 72-1) Syllabus for Laboratory Animal Technologist, p. 438.

$\dagger p<0.001$, final versus pre.

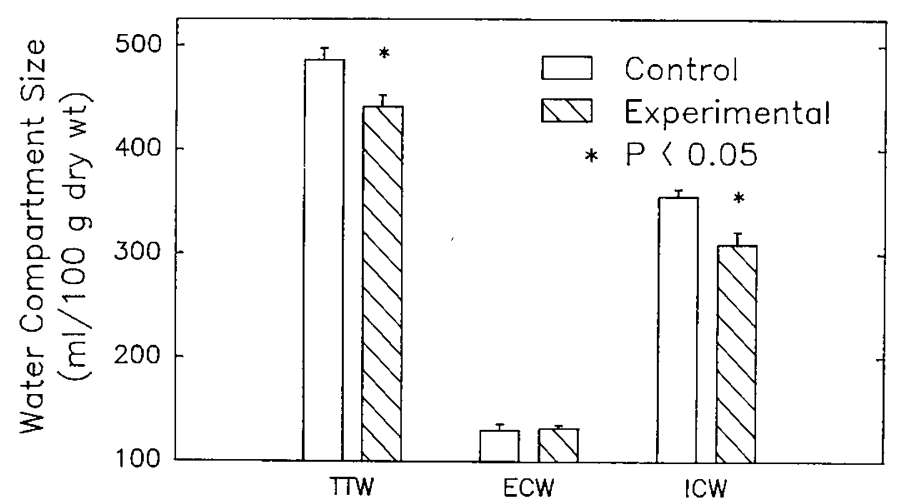

Fig. 1. This graph illustrates the size of the cerebral water compartments in the hyponatremic, taurine-replete $(n=6)$ and hyponatremic, taurine-deficient $(n=6)$ cats.

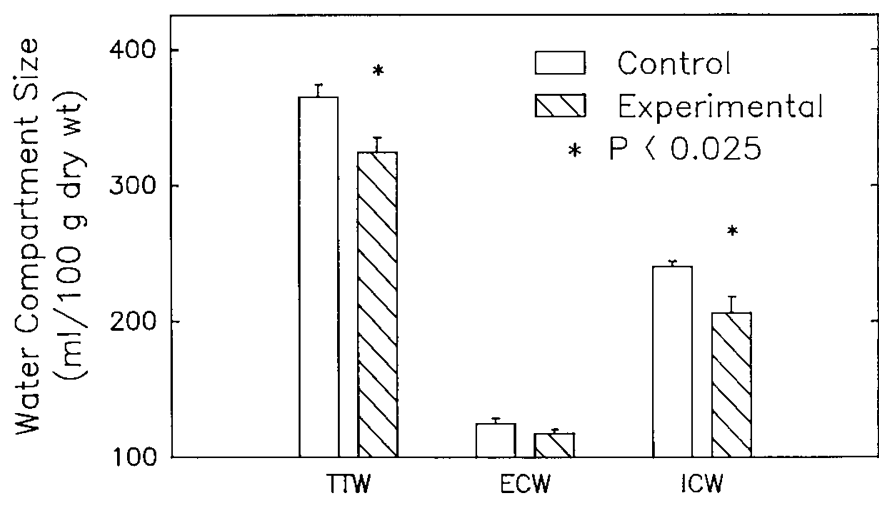

Fig. 2. This graph illustrates the size of the muscle water compartments in the hyponatremic, taurine-replete $(n=6)$ and hyponatremic, taurine-deficient $(n=6)$ cats.

Table 2. Cerebral electrolyte content (mean \pm SEM)

\begin{tabular}{ccc}
\hline $\begin{array}{c}\text { Electrolyte } \\
(\mathrm{mEq} / 100 \mathrm{~g} \text { dry wt })\end{array}$ & $\begin{array}{c}\text { Hyponatremic } \\
\text { taurine replete } \\
(n=6)\end{array}$ & $\begin{array}{c}\text { Hyponatremic } \\
\text { taurine deficient } \\
(n=6)\end{array}$ \\
\hline $\mathrm{Na}^{+}$ & $24.9 \pm 1.5$ & $25.4 \pm 1.1$ \\
$\mathrm{~K}^{+}$ & $47.1 \pm 2.2$ & $46.4 \pm 3.6$ \\
$\mathrm{Cl}^{-}$ & $15.2 \pm 0.9$ & $14.8 \pm 1.2$ \\
\hline
\end{tabular}

tration in the taurine-deficient cats would tend to increase brain water, not lower it.

The cerebral TTW was significantly reduced to $441 \pm 11 \mathrm{~mL} /$ $100 \mathrm{~g}$ dry wt in the experimental animals from a level of $486 \pm$ $11 \mathrm{~mL} / 100 \mathrm{~g}$ dry wt in the control group $(p<0.05)$ (Fig. 1). This difference was derived almost exclusively from diminished swelling of the ICW compartment, $309 \pm 12 \mathrm{~mL} / 100 \mathrm{~g}$ dry wt, experimental versus $355 \pm 7 \mathrm{~mL} / 100 \mathrm{~g}$ dry wt in the control group, $p<0.05$ (Fig. 1). In muscle tissue, similar differences in tissue water compartment sizes were observed in the experimental and control groups (Fig. 2). Thus, the TTW in the muscle of taurine-deficient animals was $324 \pm 11 \mathrm{~mL} / 100 \mathrm{~g}$ dry wt, compared to $364 \pm 9 \mathrm{~mL} / 100 \mathrm{~g}$ dry wt in the control group $(p<$ $0.025)$; similarly, the ICW compartment size was $206 \pm 12$ and $240 \pm 8 \mathrm{~mL} / 100 \mathrm{~g}$ dry $\mathrm{wt}$ in the experimental and control groups, respectively $(p<0.025)$. Thus, the osmoprotective function of taurine in hyponatremia involved both cerebral and muscle tissues.

As indicated in Table 2, the reduction in cerebral cell swelling during hyponatremia was not a consequence of differences in brain electrolyte content of the experimental or control animals. Thus, the brain $\mathrm{Na}^{+}, \mathrm{K}^{+}$, and $\mathrm{Cl}^{-}$content, expressed as $\mathrm{mEq} /$ $100 \mathrm{~g}$ dry wt, was similar in taurine-replete and -deficient cats. The final cerebral electrolyte levels were comparable to those observed in similar studies of hyponatremia in rats $(8,9)$. Although no measurements of brain electrolyte content were made in normonatremic taurine-replete and taurine-deficient cats, in view of the identical initial serum $\mathrm{Na}^{+}$concentration in the two groups, it is likely that the degree of cerebral electrolyte loss was similar in the two hyponatremic groups.

The 12-wk dietary pretreatment phase successfully lowered the plasma taurine concentration and brain and muscle tissue taurine levels in the taurine-deprived animals. As indicated in Table 3, the cerebral and muscle tissue taurine levels were reduced by 86 and $70 \%$, respectively $(p<0.01)$, in the experimental taurinedepleted versus the control group. Finally, as indicated in Figure 3 , there was a significant linear correlation between the size of the brain ICW compartment size and the cerebral taurine content $(p<0.02)$. 
Table 3. Taurine concentrations (mean \pm SEM)

\begin{tabular}{cccc} 
& $\begin{array}{c}\text { Brain } \\
(\mu \text { mol/g wet wt })\end{array}$ & $\begin{array}{c}\text { Muscle } \\
(\mu \text { mol/g wet wt })\end{array}$ & $\begin{array}{c}\text { Plasma } \\
(\mu \mathrm{mol} / 100 \mathrm{~mL})\end{array}$ \\
\cline { 2 - 4 } & $1.8 \pm 0.3$ & $2.7 \pm 0.5$ & $5.6 \pm 1.3$ \\
Hyponatremic taurine replete $(n=6)$ & $0.3 \pm 0.1^{*}$ & $0.8 \pm 0.1^{*}$ & $0.8 \pm 0.2^{*}$ \\
\hline
\end{tabular}

${ }^{*} p<0.02$, hyponatremic, taurine-deficient versus hyponatremic, taurine replete.

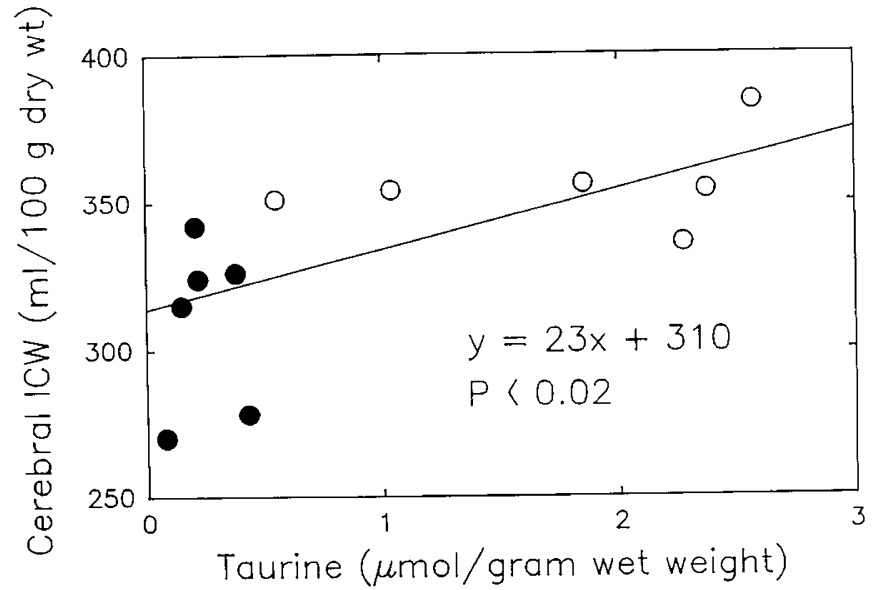

Fig. 3. This graph illustrates the significant linear relationship between cerebral taurine content and the brain ICW compartment size in hyponatremic, taurine-replete $(O)$, and hyponatremic, taurine-deficient (๑) cats.

\section{DISCUSSION}

Our results confirm our prediction that taurine functions as a cerebral osmoprotective molecule during the development of acute hyponatremia. Our regimen for producing hyponatremia was similar to previously published protocols $(10,11)$; however, ours was purposely shortened to $54 \mathrm{~h}$ to avoid early unexpected deaths in these costly animals who had been pretreated with the experimental or control diet for $12 \mathrm{wk}$. These experiments complement our earlier work in which dietary taurine deficiency augmented the plasma-to-cell osmolal gradient in the brain during chronic hypernatremic dehydration resulting in more pronounced cerebral cell shrinkage (3). Together this pair of investigations indicates that taurine is an important component of the cerebral osmoregulatory response to both extremes of disordered osmolality. They are consistent with a growing body of evidence supporting a cerebral osmoprotective role for taurine in lower species as well as mammals $(12,13)$.

The cerebral and muscle tissue taurine contents were reduced by $70-90 \%$ after $12 \mathrm{wk}$ of withholding this amino acid from the diet. The extent of taurine depletion in the brain and muscle tissues was, in fact, identical that achieved by Sturman et al. (5), using cats of similar age who were fed the same prepared diet. Although no overt clinical signs of taurine deficiency surfaced in the cats during this observation period, they confirm the tenuous nature of taurine balance in feline species due to limited biosynthesis and obligatory gastrointestinal losses of the amino acid (5). Unlike the case in chronic hypernatremia (3), there were no overt neurologic sequelae such as seizures in the hyponatremic taurine-deficient cats. In Thurston's studies of hyponatremia lasting $72 \mathrm{~h}$ in mice, the cerebral taurine level declined by $67 \%$. In our taurine-depleted cats, it is likely that no further adaptive reduction could be attained in brain taurine content beyond that created by dietary taurine deficiency.

The most likely mechanism of taurine's protective action in cerebral cell volume regulation is modification of the plasma-tocell osmolal gradient during acute reductions in serum tonicity. This would minimize the entry of water into the cytosol and limit cerebral cell swelling. The apparently small fall in the intracellular osmolality due to decreased cytosolic taurine content equal to $1.5 \mathrm{mmol} / \mathrm{kg}$ wet brain wt might be clinically significant if the changes were confined to the pericapillary astrocytes (14). However, it is conceivable that taurine may exert its osmoprotective function via additional mechanisms such as stabilization of intercapillary tight junctions that constitute the blood brain barrier $(15,16)$. Further studies will be needed to ascertain whether dietary taurine deficiency modifies the cerebral cell levels of other osmolytes during hyponatremia, such as other amino acids (4), sorbitol, and myoinositol (17). However, it is clear that our results are consistent with the hypothesis that taurine is an essential osmoprotective molecule during hyponatremia.

It is thought that modulation of brain cell taurine concentration is mediated by uptake and release of the amino acid from osmotically inactive sequestration sites such as subcellular organelles (18). However, we have shown that exogenous administration of taurine analogues affords protection against cerebral cell shrinkage during chronic hypernatremic dehydration (19). This suggests that regulation of transmembrane flux of taurine may be involved in the cell volume regulatory response to alterations in osmolality. We have, in fact, demonstrated in preliminary studies that there is increased taurine transport in synaptosomes isolated from rats with severe hypernatremia of 48-h duration (20). Further studies will be needed to assess taurine transport in vitro in synaptosomes derived from the brain of hyponatremic rats to see if the uptake of the amino acid is adaptively diminished.

The osmoprotective effect of taurine in acute hyponatremia was seen in the brain and muscle. This indicates that, unlike the situation in chronic hypernatremia, the utilization of amino acids such as taurine as osmoregulatory molecules is a more generalized adaptation to hypoosmolal disorders. This difference in extracerebral tissue response to hypo- versus hyperosmolal states requires further study. It is consistent with recent observations that reductions in cytosolic taurine content are instrumental in the erythrocyte (21) and astrocyte (22) response to acute hypoosmolal stress.

The protective effect of taurine deficiency to lessen cerebral water content during acute hyponatremia occurred in the face of equivalent levels of brain electrolyte content in taurine deficient and replete cats. Quantitatively, inorganic ions constitute the bulk of the change in solute levels within cerebral cells during chronic hyper- and hyponatremia $(23,24)$. A number of ion exchange mechanisms and selective conductive pathways are responsible for increases or decreases in the brain $\mathrm{Na}^{+}, \mathrm{K}^{+}$, and $\mathrm{Cl}^{-}$concentrations during osmolal stress states $(25,26)$. In our experiments, reduced cerebral swelling seen in taurine-deficient cats cannot be attributed to a more pronounced adaptive decrease in brain inorganic ion content. The decline in cellular electrolyte content may be a central component of the initial adaptation to hyponatremia because maximal reductions in inorganic ion concentrations are achieved within $7 \mathrm{~h}$ (27). Modification of cerebral amino acid content may play an important role during more prolonged responses to hyponatremia. 
In summary, our findings indicate that dietary taurine restriction in cats reduced cerebral taurine content and resulted in an improved capability of these animals to tolerate acute hyponatremia evidenced by decreased brain cell swelling. This effect is most likely a consequence of a decreased plasma-to-cell osmolal gradient favoring water entry into the cell. The beneficial consequence of reducing cerebral taurine content occurred in face of equivalent levels of cerebral electrolyte content. Taurine deficiency also had a beneficial impact on cell volume regulation in extracerebral tissue. We speculate that while declines in cellular content of inorganic ions may be instrumental in the initial adaptation to severe hyponatremia, reductions in brain cytosolic taurine content may be an essential part of the long-term cell volume regulatory response to hypoosmolality.

Acknowledgment. The authors thank Ms. Barbara Ho for her expert assistance in the preparation of the manuscript. In addition, they express their gratitude to Mr. Jeffrey Messing, who performed the tissue and plasma taurine determinations.

\section{REFERENCES}

1. Jacobsen JG, Smith LH, Jr 1968 Biochemistry and physiology of taurine and taurine derivatives. Physiol Rev 48:424-511

2. Thurston JH, Hauhart RE, Dirgo JA 1980 Taurine: a role in osmotic regulation of mammalian brain and possible clinical significance. Life Sci 26:15611568

3. Trachtman H, Barbour R, Sturman J, Finberg L 1988 Taurine and osmoregulation: taurine is a cerebral osmoprotective molecule in chronic hypernatremic dehydration. Pediatr Res 23:35-39

4. Thurston JH, Hauhart RE 1987 Brain amino acid, decrease in chronic hyponatremia and rapid correction causes brain dehydration: possible clinical significance. Life Sci 40:2539-2542

5. Sturman JA, Rassin DK, Hayes KC, Gaull GE 1978 Taurine deficiency in the kitten: exchange and turnover of $\left[{ }^{35} \mathrm{~S}\right]$ taurine in brain, retina and other tissues. J Nutr 108:1462-1478

6. Hayes KC, Sturman JA 1981 Taurine in metabolism. Annu Rev Nutr 1:401425

7. Finberg L, Luttrell C, Redd H 1959 Pathogenesis of lesions in the nervous system in hypernatremic states II. Experimental studies of gross anatomic changes and alterations of chemical composition of the tissues. Pediatrics 23:46-53

8. Melton JE, Patlack CS, Pettigrew KD, Cserr HF 1987 Volume regulatory loss of $\mathrm{Na}, \mathrm{Cl}$ and $\mathrm{K}$ from rat brain during acute hyponatremia. Am J Physiol 252:F661-F669

9. Verbalis JG, Drutarosky MD 1988 Adaptation to chronic hypo-osmolality in rats. Kidney Int 34:351-360

10. Ayus JC, Krothapalli RK, Armstrong DL 1985 Rapid correction of severe hyponatremia in the rat: histopathological changes in the brain. Am J Physiol 248:F711-F719

11. Ilowsky BP, Laureno R 1987 Encephalopathy and myelinolysis after rapid correction of hyponatremia. Brain 110:855-867

12. Crade JR, Olson JP, Samson FE, Nelson SR, Pazdernik TL 1988 A possible role for taurine in osmoregulation within the brain. J Neurochem 51:740745

13. Solis JM, Herranz AS, Herreras O, Lerma J, del Rio RM 1988 Does taurine act as osmoregulatory substance in the rat brain. Neurosci Letters 91:53-58

14. Rassin DK, Sturman JA, Hayes KC, Gaull GE 1978 Taurine deficiency in the kitten: subcellular distribution of taurine and $\left[{ }^{35} \mathrm{~S}\right]$ taurine in brain. Neurochem Res 3:401-410

15. Gordon RE, Shaked AA, Solano DF 1986 Taurine protects hamster bronchioles from acute $\mathrm{NO}_{2}$-induced alterations: a histologic, ultrastructural and freeze-fracture study. Am J Pathol 125:585-600

16. Cserr HE, Bundgaard M 1984 Blood-brain interfaces in vertebrates: a comparative approach. Am J Physiol 246:R277-R288

17. Lohr JW, McReynolds J, Grimaldi T, Acara M 1988 Effect of acute and chronic hypernatremia on myoinositol and sobitol concentrations in rat brain and kidney. Life Sci 43:271-276

18. Thurston JH, Hauhart RE, Naccarato EF 1981 Taurine: possible role in osmotic regulation of mammalian heart. Science 214:1373-1374

19. Trachtman H, del Pizzo R, Huxtable R, Sturman JA 1988 Taurine and Osmoregulation. II. Taurine analogues afford cerebral protection during chronic hypernatremic dehydration. Am J Dis Child 142:1194-1198

20. Trachtman H, del Pizzo R, Futterweit S 1989 Taurine transport is increased in synaptosomes isolated from rats with hypernatremic dehydration. Pediatr Res 25:349A

21. Fineham DA, Wolowyk MW, Young JD 1987 Volume sensitive taurine transport in fish erythrocytes. J Membrane Biol 96:45-56

22. Pesantes Morales H, Schousboe A 1988 Volume regulation in astrocytes: a role for taurine as an osmoeffector. J Neurosci Res 20:505-509

23. Pollack AS, Arieff AI 1980 Abnormalities of cell volume regulation and their functional consequences. Am J Physiol 239:F195-F205

24. Pierce SK 1982 Invertebrate cell volume control mechanisms: a coordinated use of intracellular amino acids and inorganic ions as osmotic solute. Biol Bull 163:405-419

25. Grinstein S, Rothstein A, Sarkadi B, Gelfand EW 1984 Response of lymphocytes to anisotonic media: volume-regulating behavior. Am J Physiol 246:C204-C215

26. Eveloff JL, Warnock DG 1987 Activation of ion transport systems during cell volume regulation. Am J Physiol 252:F1-F10

27. Sterns RH, Thomas DJ, Hernden RM 1989 Brain dehydration and neurologic deterioration after rapid correction of hyponatremia. Kidney Int 35:69-75 